como se ha podido ver, es sólo parcialmente verdadero. Los escritores chilenos (de una mínima categoría) tienen siempre presente las tendencias literarias y filosóficas de la cultura occidental, incluso cuando quieren prescindir de ellas.

Un grupo de autores sufrió en el más alto grado la influencia europea de la escuela surrealista. A través de dicha concepción realizaron una obra cuyo verdadero alcance es aún muy difícil de percibir. En todo caso abrieron un camino enteramente diferente a cuanto se intentase con anterioridad, para las nuevas generaciones, de modo que éstas pudiesen crear con una libertad $y$ universalidad de pensamiento $y$ forma que hasta ese momento no era posible imaginar en los ambientes culturales de Chile.

NICOMEdES GUZMíN

\title{
ENCUENTRO EMOCIONAL CON CHILE
}

VAmos A intentar establecer un poco de comunicación emocional con algunos asuntos naturales a nuestra tierra. Asuntos de ambiente, de horizontes, de hombría -y en esto de hombría entendámoslo todo-, es decir, lo humano, que también incluye a la mujer, severo y soberbio aguafuerte en el concierto de nuestra vida más íntima, y más pura, $\mathrm{y}$ más ancha.

La cosa es ésta:

Vamos un día por la calle y se nos ocurre darle forma a un libro. Este libro se logró con un esfuerzo de caballo, de perro, de cóndor o de puma. El título del libro lo dio un extraordinario amigo: Luis Enrique Délano. Y es éste: "Autorretrato de Chile".

Definir lo que puede ser un autorretrato de Chile quedó más o menos definido en el libro mismo. No vamos a hablar del libro, pero sí vamos a hacer referencia a algo que no solamente lo toca, sino que lo sostiene. Ocurre que hay entre sus páginas un ensayo de ese escritor, para nosotros asombroso, que se llama Manuel Rojas.

Es un trabajo de tema alto y profundo: "Chile, País Vivido". Bastaría para justificar nuestras palabras de ahora. Por ahi dice, coincidiendo con todo ese mundo que hemos visto y hemos experimentado en nuestras correrías por las veredas civilizadas y salvajes de nuestra tierra:

"He conocido hombres como de madera, como de sonrisas, como de vinagre, como de aire, como de flores, como de pezuñas; apasionados, fríos, torpes, 
inteligentes, humildes, orgullosos, poderosos y sencillos, hediondos y fragantes, tristes o alegres, conversadores o taciturnos. ¿Cuál de ellos es el chileno? Pregúntenselo al administrador o al síndico. Para mí lo eran todos, y no he conocido a todos."

Si decimos que Manuel Rojas es comúnmente magistral, no hay que extranarse. La maestría de que él ha dispuesto para contarnos lo que somos, en nuestros altibajos más sutiles, provoca el asombro a cada instante. Todos los paises americanos tienen sus espléndidos intérpretes. Chile logró varios. Pero entre estos varios, Manuel Rojas, como escritor, es lo mismo pintor que escultor. No olvidemos que la literatura encierra todas las artes. Manuel Rojas es hasta músico, compositor. Escribe con bemoles, y plasmando, y tocando, y coloreando, sufriendo y gozando, y cantando, y amando, fraguando, lleno de esos impetus del gran obrero...

¡Y qué hermoso es decir gran obrerol

Este es un secreto. Ser gran obrero es llevarse en las venas los tuétanos de la vida.

Nos enorgullece tomar como epigrafe de nuestras palabras de hoy, siquiera algunas de las palabras de Manuel Rojas. Pero es ya menester encauzarse por lo que nos hemos propuesto decir, en estos momentos, en relación con Chile.

Chile posee una nacionalidad profundamente arraigada en la tierra y un alma cuyos filamentos se aferran firmemente en aquellos grupos humanos del pueblo trabajador y anónimo.

El pueblo, este pueblo - todos lo sabemos bastante bien- es, anímicamente, una especie de arcón en donde van conservándose las tradiciones y los afectos, además de las consecuencias de las más crudas realidades.

Escultor extraordinario de la madurez de un país-escultor-masa, podríamos decir-, de la verdadera historia de una tierra en su apostura humana, vive el pueblo - no obstante- ajeno a monumentos.

Los monumentos exaltan a los militares, a los próceres con galones, a ciertos adinerados - éstos se llaman hombres de empresa-, a industriales - éstos se llaman hombres de trabajo-, a los especuladores espirituales de las potencias de una raza, pero casi nunca a quienes modesta, anónima y aguerridamente ponen su corazón, su sangre, sus sudores, sus energías todas, al servicio espontáneo de la prestancia de esa raza. 
Chile, quizá por mera casualidad, posec en la Plaza Yungay de Santiago, un bronce un tanto caprichoso, incipiente $y$ deslavado, de homenaje al roto. También una masa, al parecer de hojalata, encargada al extranjero, que recuerda la personalidad del indio Juan Godoy, arriero, pastor, descubridor de las fabulosas riquezas de Chañarcillo, en Copiapó.

Esto es algo. Pero, a estas alturas, no lo es todo.

Mas lo importante es que el monumento de exaltación del pueblo se ha estado construyendo en Chile en el correr de las páginas trabajadas por nuestros escritores.

Nos falta aún, naturalmente, la terminación de este monumento; sin embargo, va en camino de lograr en enteros rasgos su carácter.

No en vano muchos escritores hemos rumbeado -hay que insistir en esto- por los caminos de la patria, por las huellas crueles y parcas de nuestro norte, por los senderos del desierto, por los llanos del centro, por los vericuetos de la montaña, por las umbrías de la selva, por los mares que aprisionan las islas, por las callejas de los suburbios...

En nuestra empresa de buena voluntad, hemos venido haciendo un acopio más o menos maduro de metales y trigos, de sangre y anhelos, de manos callosas y esperanzas, materiales de luz que coronarán algún día la cabeza hirsuta y elevada que es el alma de nuestro pueblo.

No hemos sido los turistas que van y vienen en lance de vacia emoción.

Adentrándose en las cosas propias de la nacionalidad, aunque ellas no sean de una muy asequible belleza, se inicia la conquista de una verdad y una emoción.

Cuando fuimos al norte, lo hicimos con una curiosidad de clevadas antenas.

Suponíamos la vida del norte a través de recuerdos de infancia. No obstante, hay que decirlo: primero era necesario andar, volar y revolar los medios en que esa vida se verificara.

Más de una vez nos remontamos por las rutas infinitas del aire y fue la ocasión para enterarnos de la soledad del norte chileno y sus hombres.

La soledad chilena es asunto que tiene que ver con el rostro, con el carácter, con el cuerpo entero y rigido del territorio nacional.

Acaso sea inútil intentar una versión de esta soledad, puesto que los hombres nos la están entregando como el pan de cada día. Como aleteando, como cojeando, como mirando de soslayo, al igual que los zorzales, hay que dejarla pasar...

Pero vale la pena decirse: hemos visto el rostro de Chile, con todos sus caracteres en relieve cruel y tierno, en el curso de todas las andanzas. Hemos 
visto hombres con cara de pampa norteña, con manos como trozos de minerales; y hemos visto tierras golpeadas por los soles más chúcaros, con rostros de hombres contumaces y heroicos; y pedazos de cuarzo en que las piritas de oro parecen tener la humanidad de pupilas de las mujeres que recién aman. Hemos observado montañas con hombros soberbios lo mismo que la luz del día y vagabundos que se llevan en las espaldas todo el esplendor de la libertad y en el alma la tonada que es susurro y huracán. Hemos visto ríos que tienen andar de mocetones enamorados de su tía; y guasos que hablan lo mismo que hablaran los torrentes y los raudales si tuvieran garganta.

En todo el litoral chileno el oleaje parece tener condición de persona, con arrebato y con terneza.

Un día atravesábamos la pampa nortina en las inmediaciones de Antofagasta y a la entrada de un caserío, en medio del cabrilleo de un espejismo, se destacó la rudeza de una piedra, como un monumento que se agrandaba, A medida que nos acercábamos y el espejismo se difundía, la piedra no era piedra ni monumento, sino un rancho. Luego, no fue sino un sarmentoso indice de harapos: el objeto era una vieja, seca como momia, que alzaba la mano, pidiendo que se la llevara al otro extremo del caserío. Se movía y se quejaba con toda la energía de sus años. No hablaba, porque era muda; no oía, porque era sorda. Era, sin embargo, la continuación vivida y gesticulante del paisaje, parte del espejismo, parte de la roca, parte del ensoñar de una tierra y su destino. En ella estaba el símbolo. La pampa, su encantamiento; el rancho y la familia muerta; la vida en búsqueda permanente de la eternidad.

Hemos saboreado la "cazuela de tiuque" - así dicen- en Vallenar y en Los Vilos, de noche y de día; y hemos masticado los causeos de patitas con cebolla en Rancagua y Santa Fe; choclos cocidos en el poblado de Camiña, al interior de Iquique; brevas y quesos de cabra en la estación de Las Perdices, en los lares de Coquimbo; dulces de La Ligua en La Calera, chirimoyas en Quillota; mangos y guayabos en la estación de Pintados; choros descomunales en Puerto Edén, a un flanco del Canal Messier.

Hemos saboreado los frutos de la tierra a la vera de todos los viajes, sintiendo el viaje mismo en el sabor que nos dejaron las humildes y, a la vez, esplentes viandas.

Los limones y las naranjas de Pica tienen el gusto a beso de buena mujer. El calafate y el cordero de Magallanes tienen el zumo de una tierra mentidamente esquiva. 
Pero, como la vieja del norte, arrugada y seca lo mismo que una momia, surgen también los hombres de los pueblos y las estaciones. No propiamente el guaso de mantas coloreadas, sino el otro, el gañán de ojotas y poncho deshilachado por el tiempo y las lluvias, detenido en los andenes como incólume espantapájaros viviente, abatido por las propias estaciones de su alma oscura.

Los cargadores de los pueblos, las vendedoras de cachorros autóctonos de Chillán, las tejedoras de Dalcahue, en Chiloé; los pescadores de Antofagasta, los estibadores de Puerto Natales; los lancheros de Valparaíso; los mineros de El Teniente, Potrerillos o Chuquicamata; los arrapiezos que salen a vender copihues en Hualqui y Talcamávida; los hombres que levantan torres de madera elaborada en Monte Aguila y Coclemu; los alacalufes que salen a trocar botes de corteza vegetal por ropas viejas en Puerto Edén; los camioneros de Manantiales; los buscadores de oro de Porvenir; los bailarines de La Tirana; los balseros de Caleta Sepulcro, al ras del Canal Moraleda, todos ellos dan vitalidad a nuestros viajes, ellos son la existencia múltiple de los viajes, el rebrote más puro de la tierra, el fundamento de la fortaleza intensiva de este Chile...

Son cosas que se van sintiendo como el irrumpir de la primavera o como los aguaceros del invierno, como los chicotazos del sol y el crujidero de los salares, como la avalancha de las estrellas y el impetu de los vendavales, como la pelambre de las brisas amanecidas y el discurrir de los raudales, mientras ciertos políticos y ciertos comerciantes duermen y los ciegos tocan sus guitarras y sus violines...

Hubo épocas en Santiago de Chile en que las calles se atiborraban de cesantes y emigrados de las lejanas tierras del Norte. Venían soportando los mordiscos de horrendas miserias y de hambres.

El espectáculo conmovía las fibras de nuestra infancia. La sociedad chilena de hoy, con toda su indolencia e indiferencia, no admitiría en estos tiempos estado semejante. Los barrios populares de Santiago fueron escenarios de las trashumantes caravanas de aquellos chilenos del salitre que llegaban a capear el golpe que les asestaba el destino económico del país. Era aquel un tiempo amargo, de angustias, de plomizas ilusiones, encegueciendo la luz de los días... Por las noches, desde los galpones fiscales que hacian de albergue, no era extraño, aunque sí profundamente melancólico, oir las voces, secas, escuetas, voces como de charqui quemado que, desviando los hirientes gimoteos de algún párvulo hambriento, entonaban: 
"Canto la pampa, la tierra triste, réproba tierra de maldición, que de verdores jamás se viste ni en lo más bello de la estación.

En donde el ave nunca gorjea, en donde nunca la flor creció, ni del arroyo que serpentea el cristalino bullir se oyó."

Esta realidad cruel y sollamante que nuestra sensibilidad de niños captó en la llâga misma de aquellos días, y que nos hizo sentir la verdad que emanaba de la condición desmedrada de esos hombres y mujeres que habían dejado lo mejor de sus vidas entre las tierras acres y calientes, y bajo los cielos de horno de esas regiones norteñas, nos hizo suponer cuánto vigor guardaban en sus almas los seres del norte. La verdad social a que asistíamos con ojos y conciencia ingenuos, nos hacía ver, a pesar del candor, la vida de chicote y de saeta, el áspero curso, el escabroso ir y venir de la existencia que precedió al éxodo. La intuición nos ponía en contacto con algo grandioso y tremendo, inmenso y heroico. La imaginación no lograba aún delinear el corte topográfico de la región salitrera, pero un algo caliente y hosco, algo rebelde y ondulante, buscaba acomodo en nuestra mente para ilustrarnos del gesto de un paisaje sobre el cual lo humano era crispación de sudor y sangre.

Cuerpo tremendo y hostil, conformador de recios temperamentos humanos y cuna gris donde las esperanzas del pueblo germinaron; cuerpo doloroso que el tesón del hombre nortino aró a dinamitazos; ruda extensión en donde el esfuerzo minero se jugó las mejores cartas por el porvenir de todo nuestro luengo territorio, que lo mismo aceza aquejado por un cansancio cósmico en la zona de los desiertos, como desencadena un júbilo de savias y de lluvias en el centro, o estremece de hielo sus pies bajo los ventarrones australes, arrugada y roturada sabana, bajo la cual la ilusión de los espejismos y de los derroteros sepultó tanta osamenta de quimeras, la pampa del salitre fue el mágico tapete -ora esquivo, ora dispuesto a los más bellos azares en que la raza chilena concretó anhelos de vida y de muerte, y en que el espíritu nacional se alzó y calló por mil veces, para resurgir luego como un símbolo de contumacia, de rebeldía, de lucha y de perseverancia.

Murió, en parte, el tiempo en que el hombre de la pampa encaraba de frente, músculo a músculo, la brega con el cerro para barrenarlo, cargar los 
tiros y tronarlos. Tiempo grande, gris, epopéyico. Pero, por sobre ese tiempo, el alma del pueblo, integra y valiosa, supera las veleidades, impone sus hierros inmortales, después del duro batallar, dirigida hacia un destino ilimitado.

Los versos tristes del poeta popular alientan los ánimos de la nacionalidad hacia nuevas empresas:

"Canto la pampa, la tierra triste, réproba tierra de maldición, que de verdores nunca se viste, ni en lo más bello de la estación.

En donde el ave nunca gorjea, cn donde nunca la flor creció, ni del arroyo que serpentea el cristalino bullir se oyó..."

Y bien, asi como el labriego fue enganchado para emprender la aventura de la conquista de la pampa, he aquí que el pampino, el hijo, el nieto de aquel labriego se entrega a las ciudades en brega por la vida. Puede ser el carpintero, el cargador de los muelles, el cargador de la Vega o del Mercado. Si este último, le vemos, a plena mañana, sorteando gentío y vehículos, avanzar diestramente. Puede ser un enorme canasto atestado de frutas y verduras, el que carga encima de la cabeza. Puede ser una ruma de cajones, también cinco, seis, llenos de comestibles, superpuestos, semicruzados. Lo primero o lo segundo, es bello ver cómo el hombre equilibra su carga inmóvil sobre la cabeza. Su cuello se crispa, la transpiración se derrama de invisibles caños, puliendo el rostro rojo, de caracteres que el esfuerzo destaca en duras estrias. Profesional del esfuerzo, calzado de alpargatas, ancha faja roja a la cintura, el "roto" cargador es también artista, olímpico entre el gentio, trotando, arqueadas las piernas, rotundos los movimientos de ser imbatible.

Pero el pampino puede ser, también, en la ciudad, el asfaltador. En su nueva labor, fornido y negro, de tez ahora como compenetrada por las esencias de la brea, trabaja lo mismo que un titán durante todo el día. Músculo del pueblo, el asfaltador trabaja en grupos. Le vimos de niños y de grandes, construyendo aceras, yendo y viniendo, al hombro los barriles de alquitrán coçido, enạrẹnado, aplanando, en labor ardua y sin descanso. Mucho de la 
historia social de nuestro pueblo enmaraña su verdad profundamente angustiosa en la vida de los trabajadores del alquitrán, del asfalto. De niños, acaso, presenciáramos esa historia en la realidad misma; pero es posible que no la hayamos comprendido. Alguna vez, de madrugada, yendo al establo vecino, y mientras sus compañeros se desperezaban junto al fondo del alquitrán, vimos el pie de un asfaltador todavia dormido, sobresaliendo de bajo unos tablajes un poco alzados; pie rudo, andariego, de gruesos y deformes dedos, escasamente calzado de ojota. Pie con historia, pie conocedor de todos los caminos de la patria, pie de roto aventurero y caminador que no utiliza ferrocarriles, porque la planta es firme y robusta, curtida $\mathrm{c}$ incansable. No por casualidad un novelista chileno dijo: "Chile es un largo caminar por los cerros". Larga tierra de cerros y de llanos, aunque el pie vaya por éstos, la visión y el espíritu de nuestros hombres se aventura por las crestas de las montañas, bajo todos los climas.

Mas, en la paz de los solares, seca, enervante, mientras el sol cabecea como un macho cabrio, mientras zumban las langostas hiriendo la piel del aire, los chilenos, del norte o del sur, pueden convertirse en areneros. Ni un alma fuera de los hombres en trabajo bregador y permanente. La mañana pudo haberlos encontrado alli, dicharacheros, animosos ante la tarea endemoniada. Llegaron con sus herramientas y menestras, las barretas y las palas, las rejillas, los tarros para el agua y la "choca". La "choca" es el café del trabajador popular, del peón, del obrero callejero. Entre sus herramientas, salta siempre a la vista el tarro "choquero", ahumado, pero noble de cordialidad, cuando contiene el liquido reconfortante, que se toma en las amanecidas y en los atardeceres.

Pero he aquí que otro chileno humilde salta a la vista. Es otro andariego pobre, pero al que la vida no derrotará sino en la muerte misma. Ejercitando en todas las labores, la vejez lo encuentra por las calles suburbanas, en las mismas calles de los asfaltadores y areneros, ofreciendo su labor. Es el hojalatero. Estampa popular auténtica e irreemplazable, el hojalatero anima la visión con su presencia humilde, barbuda, haraposa. Es el servidor trashumante de los barrios pobres. A veces cojea un poco, porque cuando estuvo en los aserraderos del sur, algún tronco le malogró los huesos, o porque cuando estuvo en la pampa salitrera, alguna costra de caliche le desgarró la carne. Usa un sombrero deforme, viejo, hundido hasta las orejas y nunca falta en sus labios la colilla de papel de trigo. Está gibado, por el peso de los años. Y camina, rengueando, a la espalda la caja con las herramientas, colgante de la dieștra el hornillo humeante. Su pregón es personal y propio, delgado 
y lánguido. El aire lo toma y es como si lo agitara en un vaivén prolongado que lo conduce a las distancias. El hojalatero recorre las calles, entra a los conventillos y cités, anunciándose con el pocma roncamente melodioso de su voz gastada. Su oferta nos recuerda aquel otro pregón chileno, el pregón del vendedor nocturno, y entonces nos preguntamos qué pasión amarga, qué retorcido dolor, qué angustia crispada, qué ilimitada melancolía, qué todo aquello propio de las almas viejas contiene el pregón del vendedor nocturno.

Canto con olor a sur y a campo nutrido de las palabras: piñones, camotes, tortillas, se extiende bajo las sombras. Arrecia a veces la lluvia sobre el suburbio, entre las hilazas violentas de las aguas, y entre los resquicios del ventarrón iracundo se extiende el grito como una culebra recién azotada. En el hogar, humilde casa, junto al brasero, la abuela cuenta alguna historia de brujas, y los chicos se estremecen. El agua, entretanto, empapa las ropas del buen vendedor de la noche, garrapatea en los vidrios del farolillo, como cristalina araña. Trasciende el canasto un aroma sabroso a pulpa harinosa y dulce.

Y si el grito del hojalatero es un fragmento de iluminada vida, un poco de oscura colonia se reedita en el pregón del vendedor nocturno. El tiempo de los relojes humanos que vagaban como almas en pena por las calles del sombrío pasado, lanzando sus mondos gritos anunciadores de las horas, se revive en los gritos del hombre del farolillo y del fragante canasto. Pero parece ser también que en el grito, la tradición y las luchas de ura raza clamaran por anhelos extraterrenos.

Sería necesario dar forma integra al sentido social que guarda en si el grito de los vendedores callejeros de Chile. ¿Que la intuición no nos engañe! Pero hay en esos pregones un germen de poesía poderosa. Como en los cacharritos de greda de Quinchamali, como en los tejidos de Chiloć, como en toda manifestación de arte popular y primitivo, el pregón es una creación rotunda, una expresión categórica dentro de la simpleza, del espíritu colectivo en trance de realizaciones dotadas de espíritu. No se explica de otro modo la influencia profundamente vigorosa que tiene en las almas del suburbio.

Y bien, aunque pareciera estar de más el delineamiento objetivo de ciertos tipos populares y la referencia a asuntos también naturales al pueblo chileno, hay que reconocer cómo el estado espiritual de Chile es consecuencia de esos ciertos tipos y de esos asuntos. Exactamente por aparecer como comunes y vulgares, no se atiende a tales figuras y a:untos. Mas, nada se conocerá de un pueblo sin ir a lo puramente popular, en su expresión más simple. Ahora, exacttamente, cuando en los lances políticos se insiste en presentar al 
pueblo como motor descartado en su posición colectiva, es menester mirar con mayor fervor a la vida del pueblo para deducir la verdad de Chile y las posibilidades que se asientan en el pasado de este pueblo. La vida sin fatigas que hemos estado obligados a desplegar, nos reclama una visión conjunta de lo que pertenece al acervo de los valores populares. Quienes no tengan voluntad para mirar al pueblo chileno en sus gestos más simples, en sus actitudes menos trascendentes, en sus mínimas y muchas veces tiernas costumbres, en sus hábitos piadosos y en su tradicional bondad y generosidad, no podrán nunca conocerlo. Miremos, por ejemplo, a una viejecita que, agobiada por los años de sacrificio junto a la artesa de lavado, gibada, torpe de andar, cubierta con un añoso manto oscuro, se encamina hacia la parroquia cercana. Prototipo de la mujer heroica del pueblo, ella concreta toda una verdad histórica y humana con respecto a nuestra existencia. En ella pueden sintetizarse las virtudes todas de nuestra nacionalidad. Sin embargo, simple, humilde y anónima, camina hacia la iglesia a orar, piadosamente por los suyos. A nosotros nos parece conocerla. Suponemos su historia. Adivinamos la leyenda de su existencia compuesta por la adversidad, la tragedia, la ternura, la fe... Podría hacerse una novela con su simple vida. Su vida es una arcilla robusta y emocional, luminosa y dulce, apta para que el artista elabore en su espíritu una creación de caracteres recios y bien definidos. Una arcilla con la cual podría conformarse el rostro entero de Chile, tan caprichoso a lo largo de todo su extenso territorio.

Hábitos y cosas dan pauta para serios estudios tendientes a lograr la interpretación de un pueblo. Lo humano desplazándose en los planos aparentemente más intrascendentes, resulta a veces lo más trascendente y significativo. Podríamos hablar aquí del cargador de los muelles, de los labriegos, los camineros, los carrilanos, de la trilla, del rodeo, de los arrieros, de la chicha con harina, del mote con huesillos, de los cateadores, de los ovejeros de Magallanes, de tanta cosa simple y cordial. Pero, atendamos, más bien y, por ejemplo, a las "animitas" que se levantan como pequeños templos a la vera de cualesquicra de todos los caminos de Chile. Ellas son algo más que simples casetas de hojalata y piedras, flores naturales o de papel, cruces y velas. A la vera de las rutas carreteras o férreas, animadas por el fervor de las mujeres de los campos, de los desiertos, a la salida de los pequeños pueblos o en los extramuros de las grandes ciudades, parecen guardar el latido de todas las almas que les han dispensado su cuidado. Las flores secas, las coronas de papel descolorido, las velas chorreantes palpitan como en una especie de agostamiento doloroso y místico. El simple objeto, el vulgar elę- 
mento, las pequeñas cosas que el ojo profano no ve o las observa con malicia, pierden aquí su humildad material para trocarse, acaso, en cosas vivientes y emocionadas.

Junto a un camino solitario donde parece que, por años, no ha transitado un alma, a la vera de una ruta calcinada, achicharrada por el sol del estío y de donde hasta las lagartijas parecen haber huido, hay la caseta de una animita. Existe allí desde hace largo tiempo y señala exactamente el lugar donde falleció, de una u otra manera, un rústico hombre chileno. La soledad vibra en el lugar. ¿En qué hora invisible, en qué instante de tiernas luces, en qué encrucijada milagrosa de segundos, el sésamo ábrete de la piedad arrebató sus dominios a la soledad para venir aquí, a la caseta de la animita, a prender unas velas, a rezar una oración y a rogar por la salud de un enfermo rural? El camino no acusa huellas. Pero es cierto que alguien vino desde lejos a depositar aquí unas velas, unas flores y unas plegarias. Aún hay algo como fluctuación de voces en el aire caldeado. Una como humedad de alma humana que intentara refrescar la atmósfera. Una como sensación de evaporadas lágrimas. Los sentimientos de quien vino es como si hubiesen quedado prendidos al lugar en donde encontró el fin de sus días un rústico labriego chileno. Y son estos sentimientos, acaso, los que insuflan vida a lo que es muerte...

Aquí hay una virtud en marcha. Virtud simple, pero que es verdad, que es poder cierto, que es ternura y fervor humano, que es deseo de permanencia en la vida, de continuidad, de prolongación, de futuro.

Todas estas cosas quedan fuera de los programas turísticos. Se pierden en proyecciones que nada tienen que ver con una intención de conocer y entender a un pueblo.

Chile es rico en materiales de observación y análisis que permitan sorprenderle en toda su musculosa desnudez espiritual. Nuestras palabras no pretenden más que hacer suponer este espíritu. Nos hemos referido a aspectos simplísimos de nuestra vida popular que pudieran ser pintorescos, pero nunca dejarán de ser intimamente humanos. Es importante en la vida de los pueblos el conocimiento de sus más significativas fechas históricas, el modo cómo se ganó una batalla por su libertad, los hechos que dieron como consecuencia éste o aquel acontecimiento político, los perfiles grandiosos de algún prócer.

Mas bajo todo esto se mueven y se agigantan otras cosas, a cuyo conocimiento huimos: lo que puede ser base más seria de hẹrmandad, de fraternidad, de comprensión, 
No hay pueblo que, al mismo ritmo de sus luchas públicas, no se encuentre librando una lucha intima. Esta lucha se encuentra en las costumbres y en la simpleza de la existencia popular. Simpleza que deriva en grandes gestas, como la gesta del salitre en Chile, o del carbón, o del cobre, simpleza en que se recluyen la verdad, la esperanza, los bríos y la bizarría de una nacionalidad.

Comprendamos al pueblo, y habremos comprendido una nacionalidad. Los acontecimientos pasan. El pueblo y su conducta, por muy anónima que ella sea, abren el paso a lo eterno.

Chile se construye sobre el alma misma del pueblo y sus detallamientos más simples, pero más respetables. De aquí nacen sus empresas colectivas, siempre en brega, en medio de una soledad territorial ajena a influencias espirituales.

Y de aquí emana su cultura, sus inquietudes de nacionalidad tierna y soberbia, a la vez, su desprendimiento, su generosidad siempre constatable.

Y para terminar... Teniamos entre manos viejos apuntes que nos habrian servido para dar gran cuerpo temporal a lo dicho... Cuán saludable habría sido hablar, como lo ha hecho Manuel Rojas con sus asombrosos personajes, el consejero sempiterno de Pellín Queltehue, por ejemplo, de Críspulo Pérez, el desvalijador de lanchas, de Punta Arenas, de don Froilán Geldez, el pionero de Futaleufú y de multitud de seres con nombre y sin nombre, de cosas con apelativo y sin apelativo, con quienes hemos contraído amistad profunda a través de nuestros vagabundajes, amistad de manos, de ojos, de miradas, de ternura; amistad toda ella confundida con la verdad asombrosa de nuestra tierra y de nuestras gentes...

Será para otra vez, como nos dijo una muchacha sorprendente de la ciudad de Chile Chico, en los momentos mismos en que subíamos al avión que nos conduciría a Santiago.

\section{ENRIQUE LAFOURCADE}

\section{LA DOCTRINA DEL OBJETO ESTETICO}

\section{La creación artistica no es un azar.}

LA CREACrón, dentro del dominio del arte, no puede ser un simple azar, un acto mágico puro, una promoción nueva, inasible. Debe estar presidida por una voluntad formal, por un cierto oficio y control sobre lo creado. 